\title{
COMPARAÇÃO ENTRE VIDEOGRAFIA E FOTOGRAFIA AÉREA PARA DIAGNÓSTICO DA VEGETAÇÃO EM AMBIENTE URBANO DE PIRACICABA, SP ${ }^{1}$
}

\author{
Ivan André Alvarez², Demóstenes Ferreira da Silva Filho ${ }^{3}$, Hilton Thadeu Zarate do Couto ${ }^{3}$ e \\ Jefferson Lordello Polizel ${ }^{3}$
}

\begin{abstract}
Resumo - No planejamento urbano, um bom diagnóstico da presença de vegetação serve como subsídio na elaboração de um plano de ação para implantar espaços verdes e administrar a cobertura arbórea existente. Este estudo compara a eficiência das técnicas de videografia e fotografia aérea para caracterizar vegetação urbana por meio do Índice de Cobertura Vegetal em Áreas Urbanas (ICVAU) e do Índice de Verde por Habitante (IVH). O local do estudo situa-se na cidade de Piracicaba, Estado de São Paulo, Brasil. Para validar os métodos, foram utilizados Exatidão Geral e Índice de Kappa. A Exatidão Global foi de 88\% para a fotografia aérea e de 93\% para a videografia, enquanto que o Índice de Kappa foi acima de 85\%, para as duas técnicas. Esses valores mostraram que caracterização da vegetação urbana foi feita de maneira coerente com a realidade, tanto para fotografia aérea, como para videografia. Os valores obtidos foram: ICVAU = 18,41\% (fotografia aérea) e 16,48\% (videografia); IVH = 116,93m2/hab (fotografia aérea) e 65,21 m2/hab (videografia). O ICVAU e o IVH mostraram que essa é uma área com uma porcentagem razoável de verde. A videografia foi mais eficiente para calcular o (ICVAU) e o (IVH) que a fotografia aérea. A videografia também foi o método mais adequado para avaliação para o estudo de árvores de calçadas.
\end{abstract}

Palavras-chave: Palavras chaves: Arborização urbana, Geoprocessamento e Sensoriamento remoto.

\section{COMPARISON BETWEEN VIDEO AND PHOTOGRAPHIC AIR FOR DIAGNOSIS OF VEGETATION IN THE URBAN ENVIRONMENT PIRACICABA, SP}

\begin{abstract}
In urban planning, a good diagnosis of the presence of vegetation serves as a basis to draw up a plan of action to implant green spaces and manage the existing tree cover. This study obtained the plant cover by Urban Areas Index (PCUAI) and by Greenery per Inhabitant Index (GII). Videography was compared to aerial photography of the same area in the city of Piracicaba, São Paulo State, Brazil, by means of the General Exactness and Kappa Index obtained by SIG programs. The values obtained were: PCUAI $=18.41 \%$ (aerial photography) and 16.48\% (videography); GII = 116.93m2/inhab (aerial photography) and 65.21 m2/inhab (videography). The PCUAI and GII showed that the studied area had a reasonable percentage of greenery. Videography was shown to be viable as an alternative means of obtaining plant cover data, especially sidewalk trees cover.
\end{abstract}

Keywords: Urban forestry; Gis e Videography.

\section{INTRODUÇÃO}

A presença de vegetação nas cidades tem sido considerada um sinônimo de qualidade de vida. As cidades são ambientes alterados que possuem vegetação remanescente de áreas naturais ou que estão em áreas implantadas. A cobertura vegetal apresenta-se com várias feições em áreas públicas (parques, jardins e praças), em torno de córregos e rios ou em áreas privadas (residências e indústrias).

\footnotetext{
${ }^{1}$ Recebido em 14.12.2007 e aceito para publicação em 02.03.2010.

22 Empresa Brasileira de Pesquisa Agropecuária - Petrolina, PE. E-mail: <ivan.alvarez@cpatsa.embrapa.br>.

${ }^{3}$ Departamento de Ciências Florestais, ESALQ, USP. Escola Superior de Agricultura "Luiz de Queiroz" (ESALQ), Universidade de São Paulo (USP) - Piracicaba, SP.E-mail: <htzcouto@esalq.usp.br>.
} 
No planejamento urbano, é necessário realizar um bom diagnóstico da presença de vegetação como subsídio para elaborar plano de ação que vise à implantação de espaços verdes e manejo da arborização existente. O verde é o elemento mais frágil nas cidades, uma vez que sofre diretamente os efeitos da ação antrópica, representada pelas pressões da urbanização e do adensamento populacional. Para garantir um mínimo de bem-estar à população, é importante quantificar os elementos relacionados à cobertura vegetal presentes nas cidades.

Guzzo (1999) indica o Índice de Cobertura Vegetal em Área Urbana (ICVAU) (expresso em porcentagem) como um parâmetro para avaliação da presença do verde na cidade; este índice representa a proporção de área coberta com vegetação em função da área total estudada, abrangendo áreas públicas e particulares. O Índice de Verde por Habitante (IVH) é também um bom parâmetro (em $\mathrm{m}^{2} / \mathrm{hab}$ ) e expressa a quantidade de cobertura vegetal dividida pelo número de habitantes do local. Esses índices citados acima podem ser utilizados como padrões de referência de qualidade de vida para a população que habita um determinado local.

A videografia vem sendo utilizada como uma técnica de sensoriamento remoto que permite captar imagens e analisá-las por meio de computador. Atualmente, o que viabiliza o uso da videografia como sensor remoto são os sistemas de gravação e o processamento das imagens por meio de computadores (Silva Filho, 2006; Powell, R.L. et. al., 2007).

Pompermayer Neto (2002) destacou que o custo dos sistemas de vídeo é uma grande vantagem em relação a outros sensores, enquanto que Silva Filho (2006) ressaltou como vantagem a visualização imediata das imagens, permitindo a separação das faixas do espectro eletromagnético visível de 400nm a 700nm e as faixas do infravermelho próximo (700nm a 1100nm). Couto et. al. (2000) acrescentaram, ainda, como vantagens: a) a possibilidade de identificação e correção de problemas com rota e obtenção das imagens; b) a integração do sistema de videografia com GPS e com SIG; c) a obtenção de grande quantidade de imagens.

A refletância na faixa do infravermelho próximo (700nm - 1350nm) é a que melhor expressa o limbo foliar. Segundo Shimabukuro (1996), essa faixa é adequada para classificação da vegetação, podendo, portanto, melhor diferenciar os tipos de vegetação: rasteira, arbórea, folha fina, folha grossa, vigor fenológico, valor de biomassa, entre outros.

Dessa maneira, este trabalho tem como objetivo comparar a eficiência de utilização de videografia ou de fotografia aérea para obtenção do Índice de Cobertura Vegetal em Áreas Urbanas (ICVAU) e do Índice de Verde por Habitante (IVH).

\section{MATERIAL E MÉTODO}

\subsection{Local de estudo}

O estudo foi realizado no bairro Santa Cecília, localizado na zona leste do Município de Piracicaba, distando cerca de $3,5 \mathrm{~km}$ do centro.

\subsection{Levantamento da cobertura verde}

A cobertura verde do bairro foi evidenciada por meio de fotografia aérea e de videografia, para se obter o Índice de Cobertura Vegetal em Área Urbana (ICVAU) e o Índice de Verde por Habitante (IVH), segundo Guzzo (1999). A comparação entre os dois métodos para obtenção dos índices foi realizada no levantamento da cobertura vegetal dos espaços verdes, dividida em espaço verde de arborização viária, espaço verde de espaços livres públicos e espaço verde de locais particulares.

\subsection{Equipamentos, software e local de trabalho}

O trabalho de geoprocessamento foi realizado no Laboratório de Métodos Quantitativos do Departamento de Ciências Florestais da ESALQ/USP. O sistema de Informações geográficas (SIG) utilizado foi a ferramenta de processamento digital disponíveis do ERDAS Imagine versão 8.5 do fabricante Leica. O software ADOBE PHOTOSHOP versão 7.0 auxiliou na montagem e corte das imagens.

\subsection{Fotografia aérea}

As fotografias aéreas verticais (pancromática) datadas de dezembro de 2.000 foram utilizadas com uma escala de 1:30.000. Essas fotos já foram adquiridas digitalizadas. A área exata de estudo foi definida pelo recorte da imagem digital da cidade de Piracicaba, por meio do programa de computador Adobe Photoshop, aproveitando que o mosaico para a cidade já havia sido montado no mesmo programa. 


\subsection{Videografia}

As cenas obtidas para realização da videografia foram feitas com a câmera de vídeo digital Duncantech MS-3100, fixada em uma abertura no piso do avião. O sobrevôo na área de estudo foi feito em um avião CESSNA modelo 180, a uma altitude de $2.300 \mathrm{~m}$ do nível do mar e $1.700 m$ do nível do solo. No horário do vôo, o céu apresentava ótimas condições de visibilidade e nenhuma nuvem.

As imagens foram capturadas com um tamanho de pixel que resultou numa resolução espacial de aproximadamente $1 \mathrm{~m}$. Foram adquiridas 55 cenas e, dentre elas, foram selecionadas 24 para compor a área de estudo. Um mosaico das imagens foi criado pelo programa Adobe Photoshop.

\subsection{Georreferenciamento das imagens}

Para georreferenciamento das imagens obtidas pela fotografia aérea e pela videografia, foram tomadas as coordenadas no campo, com um receptor GPS (Global Positioning System).

Após a obtenção das coordenadas, elas foram transformadas de coordenadas geográficas para o sistema métrico UTM, utilizado pelo software, para referenciamento das imagens.

\subsection{Classificação das imagens}

A classificação das imagens, tanto as obtidas das fotografias aéreas, como as da videografia, foi realizada na seguinte sequencia:

1)Definiu-se um conjunto de amostras nas imagens que representassem o conjunto de classes;

2)verificações preliminares em campo para reavaliar e obter as coordenadas das amostras;

3)classificação supervisionada em cada imagem com a utilização do programa Erdas;

4)informação ao programa de cada classe definida no conjunto de amostras;

5)Reambulação - visita ao campo para validar a classificação;

6)Poligonização - conversão de imagem raster (matriz) para vetorial.
As amostras de treinamento, para se definir o tipo de subclasse, foram delineadas por polígonos, em tela, sobre áreas que representavam o tipo de cobertura de solo definida pela visita à área de estudo.

Para classificação supervisionada, empregou-se o algoritmo de máxima verossimilhança (Jensen, 1996).

Para se ter certeza de que a classificação realizada foi coerente com a realidade, calculou-se a Exatidão Global (EG) (Congalton \& Green, 1999) e o Índice de Kappa (Landis \& Koch, 1977).

A análise das imagens foi realizada pelo software ERDAS e gerou mapas digitais que expressou as diferentes coberturas de solo. Os mapas foram criados tanto a partir da fotografia aérea, quanto da videografia.

\section{8 Índice de Cobertura Vegetal em Áreas Urbanas (ICVAU)}

O ICVAU foi medido em porcentual, sendo ele a proporção das áreas públicas e particulares cobertas com vegetação em função da área total estudada.

\section{9 Índice de Verde por Habitante (IVH)}

O Índice de Verde foi medido em metros quadrados por habitante (IVH), sendo a quantidade de cobertura vegetal dividida pelo número de habitantes do local (obtida a partir do Senso de 2000, IBGE, 2000).

\section{RESULTADOS E DISCUSSÃO}

\subsection{Fotografia aérea}

A figura 1 mostra os resultados obtidos pelo mosaico das fotografias aéreas. As áreas com cobertura vegetal concentraram-se mais na área de preservação permanente, em torno do córrego, embora ainda não respeitando a faixa prevista em lei, e em alguns locais, com presença de chácaras. Estes fatos foram confirmados na conferência em campo.

\subsection{Videografia}

O mosaico obtido pela videografia (Figura 2) demonstra que a vegetação aparece mais destacada (em vermelho), o que permite compará-la de uma maneira mais clara com os elementos arquitetônicos. Distinguem-se melhor os espaços de áreas com forrações e com impermeabilização.

Revista Árvore, Viçosa-MG, v.34, n.4, p.691-698, 2010 


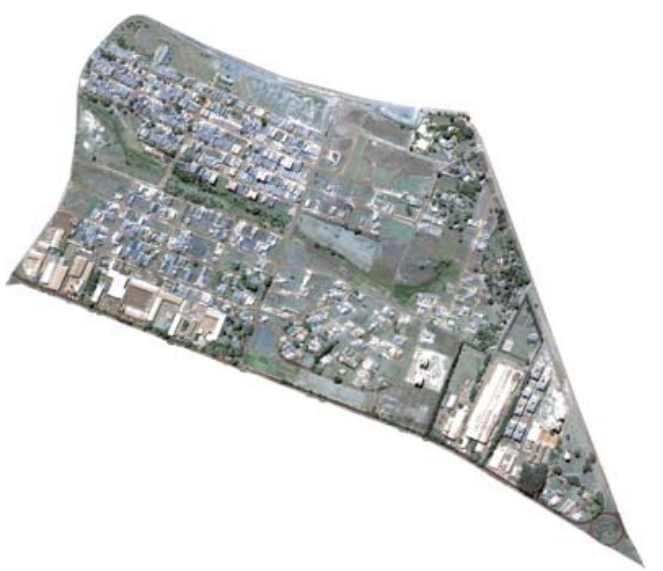

Figura 1 - Fotografia aérea do Bairro Santa Cecília, Piracicaba, Estado de São Paulo, em 2001.

Figure 1-Aerial photographs of the Santa Cecília neighborhood, Piracicaba, State of São Paulo,

\subsection{Classificação das imagens}

A verificação em campo e a confirmação em tela geraram 51 subclasses na fotografia aérea e 50 na videografia, para cada classificação de cobertura de solo.

O número de pontos amostrados, definidos pelo cálculo, foi de 41 pontos distribuídos na área de estudo.

\subsubsection{Fotografia aérea}

A classificação do tipo de cobertura do soloda fotografia aérea do bairro Santa Cecília é apresentada por área e por proporção, no Tabela 1.

A Exatidão Global da classificação obtida pela fotografia aérea da área é igual a 88\%, o que é considerado bom para padrões de avaliação que utilizam fotografia aérea como parâmetro de avaliação da cobertura vegetal (CONGALTON \& GREEN, 1999).

\subsubsection{Videografia}

A classificação do tipo de cobertura do solo das imagens do bairro Santa Cecília é apresentada por área e por proporção, no Tabela 2. A Exatidão Global da classificação obtida pela videografia da área é igual a 93\%. Este valor, acima de 90\%, supera o obtido pelo processamento da fotografia aérea, diminuindo a confusão entre os índices de cobertura dos solos analisados. Segundo Congalton e Green (1999), esse valor é considerado ótimo para avaliar a exatidão da amostragem.

As diferenças entre os valores obtidos a partir de fotografia aérea e de videografia x tanto podem ser decorrentes das diferentes características espectrais

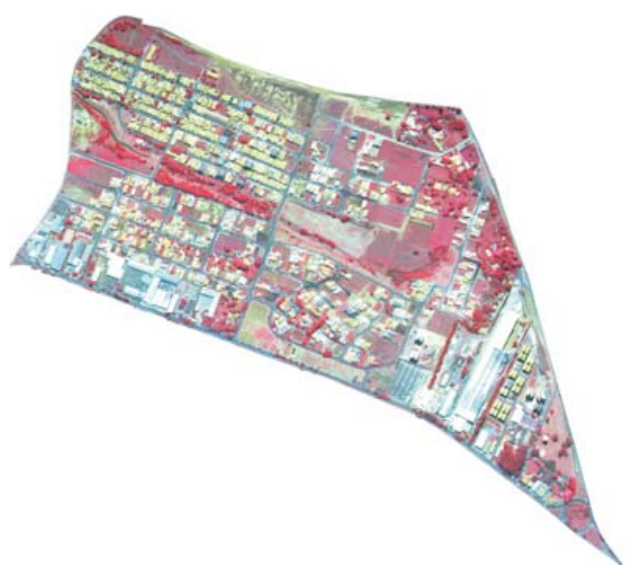

Figura 2 - Videografia do bairro Santa Cecília, Piracicaba, Estado de São Paulo, em 2003.

Figure 2 - Videography of the Santa Cecília neighborhood, Piracicaba, State of São Paulo, Brazil, in 2003.

que interpretam as reflectâncias com menor (fotografia) ou maior (videografia) riqueza, como devidas às variações entre os anos em que foram feitas a fotografia aérea, 2000, e a videografia, 2003. Pela análise da Exatidão Global fica claro que a videografia pode ser utilizada com maior segurança, além das vantagens do menor custo e de fornecer acessibilidade instantânea às imagens, se comparado à fotografia aérea que normalmente fica na dependência de que uma empresa realize o vôo e disponibilize as fotos.

Tabela 1 - Classificação do tipo de cobertura de solo do Bairro Santa Cecília, Piracicaba, Estado de São Paulo, a partir de fotografia aérea, em 2001

Table 1 - Classification of soil covers in the Santa Cecília neighborhood, Piracicaba, State of São Paulo, Brazil, from aerial photography, in 2001

\begin{tabular}{lcc}
\hline Tipo de cobertura do solo & Área $\left(\mathrm{m}^{2}\right)$ & Proporção (\%) \\
\hline Asfalto/Concreto & $308.311,79$ & 25,14 \\
Rua de terra com pedregulho & $49.867,88$ & 4,07 \\
Telhado de residência & $155.139,80$ & 12,65 \\
Telhado de galpão & $62.263,90$ & 5,08 \\
Solo exposto & $135.230,07$ & 11,03 \\
Leito de rio & $62.375,19$ & 5,09 \\
Forração & $226.220,24$ & 18,45 \\
Árvore/Arbusto & $225.801,50$ & 18,41 \\
Superfície líquida & $1.096,24$ & 0,09 \\
Totais & & \\
Ambiente construído & $525.715,49$ & 42,87 \\
Solo exposto & $247.473,14$ & 20,18 \\
Forração & $226.220,24$ & 18,45 \\
Cobertura arbórea & $225.801,50$ & 18,41 \\
Superfície líquida & $1.096,24$ & 0,09 \\
\hline
\end{tabular}




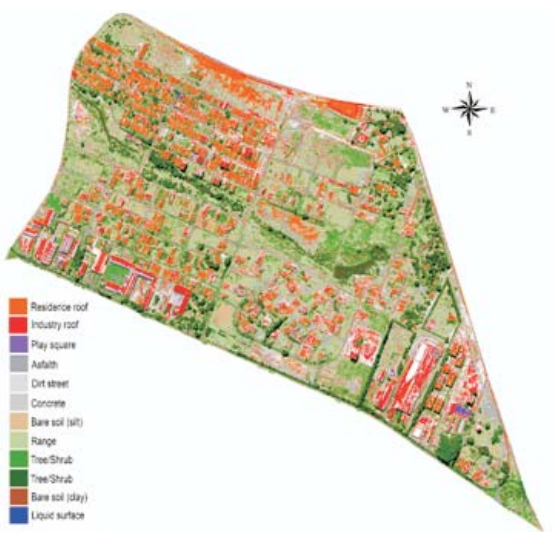

Figura 3 - Modelo digital por fotografia aérea do Bairro Santa Cecília, Piracicaba, Estado de São Paulo, em 2001.

Figure 3 - The digital model by aerial photography of the Santa Cecília neighborhood, Piracicaba, State of São Paulo, Brazil, in 2001.

Tabela 2 - Classificação do tipo de cobertura de solo do Bairro Santa Cecília, Piracicaba, Estado de São Paulo, a partir de videografia, em 2003.

Table 2 - Classification of soil covers in the Santa Cecília neighborhood, Piracicaba, State of São Paulo, Brazil, from videography, in 2003.

\begin{tabular}{lcc}
\hline Tipo de cobertura do solo & Área $\left(\mathrm{m}^{2}\right)$ & Proporção (\%) \\
\hline Asfalto/Concreto & $353.463,15$ & 29,61 \\
Rua de terra com pedregulho & $56.305,44$ & 4,72 \\
Telhado de residência & $224.811,72$ & 18,83 \\
Telhado de galpão & $129.999,16$ & 10,89 \\
Solo exposto & $80.069,06$ & 6,71 \\
Leito de rio & $39.969,68$ & 3,35 \\
Forração & $110.778,67$ & 9,28 \\
Cobertura arbórea & $196.724,00$ & 16,48 \\
Superfície líquida & $1.547,02$ & 0,13 \\
Totais & & \\
Ambiente construído & $708.274,03$ & 59,34 \\
Solo exposto & $176.344,17$ & 14,77 \\
Forração & $110.778,67$ & 9,28 \\
Cobertura arbórea & $196.724,00$ & 16,48 \\
Superfície líquida & $1.547,02$ & 0,13 \\
\hline
\end{tabular}

\subsection{Matriz de erro e Índice Kappa}

O Índice de Kappa demonstrou que a fotografia aérea e a videografia estão acima de 85\%; distinguindo bem as classes de cobertura do solo, nos dois anos em que as imagens foram feitas. A classe de superfície líquida (piscina) teve amelhor exatidão estimadanas duas formas de imagem obtidas. Porém, havia menos exatidão entre a separação do que era asfalto e solo nu na fotografia aérea, em relação à videografia.

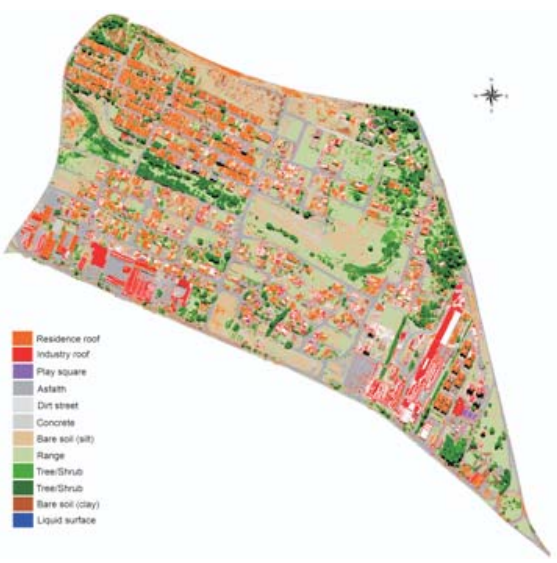

Figura 4 - Modelo digital por videografia do Bairro Santa Cecília, Piracicaba, Estado de São Paulo, em 2003.

Figure 4-Digital model by videography of the Santa Cecília neighborhood, Piracicaba, State of São Paulo, Brazil, in 2003.

Comparando-se com os dados de EspíritoSanto e Shimabokuro (2005), que estudaram o Índice de Kappa (80,9\%) e a Exatidão Global $(84,5 \%)$ para a Floresta Nacional de Tapajós, os valores para a amostragem conferida em campo foram altos, assim como para a distinção entre as classes de cobertura do solo.

Para área urbana, pode ser considerado um resultado promissor, uma vez que há pouco erro entre o mapeamento e os valores obtidos com os pontos da verdade terrestre (VT).

\subsection{Cálculo do Índice de Cobertura Vegetal em Áreas Urbanas (ICVAU) e do Índice de Verde por Habitante (IVH)}

Para calcular o ICVAU, obtêm-se a proporção de manchas verdes de duas formas: a primeira possibilidade é optar por ser essa proporção "as manchas de vegetação visíveis a olho nu” e extrapolar para o que se extrai de verde de fotografia aérea ou de videografia (forração + cobertura arbórea), por meio de processamento digital (Tipo 1); a segunda possibilidade é considerar como “proporção de manchas verdes” apenas as vegetações de porte arbóreo e arbustivo visíveis a olho nu e extrapolar para o que se extrai desse tipo de mancha verde de fotografia aérea ou de videografia, por meio de processamento digital (Tipo 2). Foram testadas as duas formas e os resultados foram os mesmos.

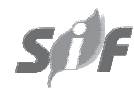

Revista Árvore, Viçosa-MG, v.34, n.4, p.691-698, 2010 
Tabela 3 - Indicadores de exatidão, em porcentagem, das matrizes de erro das imagens de fotografia aérea e de videografia do Bairro Santa Cecília, Piracicaba, Estado de São Paulo.

Table 3 - Exactness indicators, in percent, for error matrixes of aerial photography and videography images of the Santa Cecília neighborhood, Piracicaba, State of São Paulo, Brazil.

\begin{tabular}{|c|c|c|c|c|}
\hline \multirow{2}{*}{$\begin{array}{l}\text { Imagem } \\
\text { Classe } \backslash \text { Exatidão }\end{array}$} & \multicolumn{2}{|c|}{ Fotografia Aérea } & \multicolumn{2}{|c|}{ Videografia } \\
\hline & $\begin{array}{l}\text { Exatidão }(+\mathrm{i}) \\
\text { (omissão)(\%) }\end{array}$ & $\begin{array}{l}\text { Exatidão }(+\mathrm{i}) \\
\text { (inclusão)(\%) }\end{array}$ & $\begin{array}{l}\text { Exatidão (+i) } \\
(\text { omissão)(\%) }\end{array}$ & $\begin{array}{l}\text { Exatidão }(\mathrm{i}+) \\
\text { (inclusão) }(\%)\end{array}$ \\
\hline Asfalto & 91,90 & 60,75 & 92,28 & 88,90 \\
\hline Piso concreto & 84,71 & 38,61 & 45,41 & 75,15 \\
\hline Telha cerâmica & 95,46 & 88,25 & 75,34 & 77,55 \\
\hline Telha escura & 0 & 87,85 & 0 & 45,57 \\
\hline Telha clara & 86,15 & 59,77 & 94,87 & 78,72 \\
\hline Telha cimento & 95,02 & 68,00 & 99,61 & 76,14 \\
\hline Solo exposto & 54,57 & 83,52 & 82,41 & 92,50 \\
\hline Árvore/arbusto & 88,16 & 95,81 & 91,11 & 98,67 \\
\hline Superfície líquida & 100 & 100 & 99,25 & 100 \\
\hline Sombra & 91,39 & 52,81 & 99,62 & 39,71 \\
\hline Fundo & 100 & 99,48 & 100 & 100 \\
\hline Kappa geral & \multicolumn{2}{|c|}{$86,87 \%$} & \multicolumn{2}{|c|}{$85,70 \%$} \\
\hline
\end{tabular}

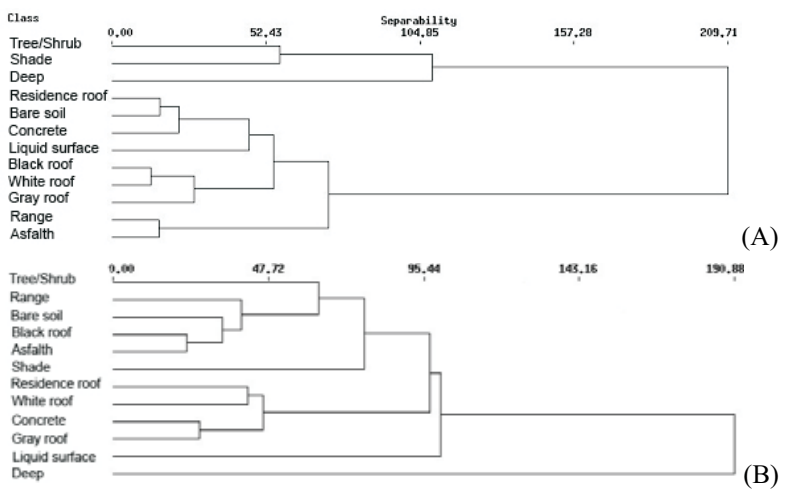

Figura 5 - Dendograma da fotografia aérea (A) e videografia (B) do Bairro Santa Cecília, Piracicaba, Estado de São Paulo.

Figure 5 - Dendogram of the aerial photography (A) and videography (B) of the Santa Cecília neighborhood, Piracicaba, State of São Paulo, Brazil.

O ICVAU e o IVH mostraram que essa é uma área com um bom porcentual de verde, ICVAU $=18,41 \%$ (fotografia aérea) e 16,48\% (videografia); IVH=116,93m²/hab (fotografia aérea) e $65,21 \mathrm{~m}^{2} / \mathrm{hab}$ (videografia), sendo esse último resultado mais coerente com a realidade em campo (Alvarez, 2004). Como a área estudada não era populosa, o IVH é bem alto, se comparado a outros locais com características semelhantes, como é o caso de Vinhedo (Harder et.al., 2006) e Jaboticabal (Silva Filho et.al., 2002). Cabe lembrar que tanto a proporção de áreas com cobertura arbórea, como a proporção de áreas com forração incluem as áreas particulares; muitas delas são terrenos sem construção. Em alguns casos, os terrenos não só possuem mato, mas também solo exposto, o que não entrou no percentual de áreas com forração.

Analisando-se os dados contidos nas Tabelas 1, 2 e 3, verificou-se que as áreas construídas aumentaram 16,47\%, entre esses anos, ou seja, vários terrenos vazios foram ocupados com construções. Nos tipos de cobertura “telhado de residência” e "telhado de galpão", o aumento foi de 11,99\%, o que significa uma grande participação no aumento global de ambiente construído.

A avaliação do percentual dos vários tipos de cobertura verde mostra que houve diminuição da área com cobertura arbórea e com forração. Os fatores que contribuíram para tal diminuição foram comparados aos dados de campo, obtidos por Alvarez et. al. (2005), nos levantamentos de 2001 e 2003, mostrando que o aumento na ocupação dos terrenos vazios e o manejo das árvores de grande porte (poda) tiveram grande influência nesse resultado. Também houve uma discreta diminuição do diâmetro médio de copa de árvores, nesse período de 2001 para 2003, embora o número de árvores por quilômetro não modificou de forma homogênea. O número de árvores com diâmetro maior que 6 metros diminuiu de $14 \%$ para $13 \%$ e o número de árvores com diâmetro menor que 3 metros aumentou de 54\% para $57 \%$. Verifica-se, então, que as árvores de rua não contribuíram para o aumento da cobertura vegetal no bairro como um todo. 
Para comprovar a validade do levantamento da cobertura vegetal utilizaram-se os dados de árvores por quilômetro e de diâmetro das copas de árvores obtidos por Alvarez et. al. (2005). Este autor utilizou 3 classes de diâmetro (menor que $3 \mathrm{~m}$; entre 3 e $6 \mathrm{~m}$ e maior que $6 \mathrm{~m}$ ). Supondo-se que se multiplicasse o valor de arv/ $\mathrm{km}$ pelo porcentual de cada classe de diâmetro médio, encontrar-se-iam os seguintes valores: em 2001, para a maior classe de diâmetro, 5,42 arv/km e para a menor, 20,92 arv/ km. Em 2003, para a maior classe de diâmetro, o valor seria 5,17 arv/km e para a menor classe, 22,69 arv/ km.

Dos 25,76\% de cobertura verde total (forração + cobertura arbórea), em 2003, sabe-se que 1,35\% é de verde de acompanhamento viário (ALVAREZ, 2004), mas não se pode precisar o quanto da cobertura arbórea e forração pertence a espaços livres de uso público e a áreas particulares (residências, comércio, indústria e terrenos). Além disso, para se ter uma idéia de qual é a contribuição total da arborização viária, necessita-se saber o quanto há de arborização de calçadas. Assim, por meio do levantamento de campo, estima-se a arborização de calçadas e, por meio de levantamento remoto, estima-se todo o sistema viário, comparando-se os dois métodos.

O cálculo da copa de árvore por meio do levantamento de campo é feito a partir dos dados de classe de diâmetro (ALVAREZ et. al., 2005). Assume-se uma copa circular e com os dois diâmetros iguais. O cálculo da superfície de copa é feito por:

$$
\begin{aligned}
& \mathrm{S}_{\mathrm{c}}=\pi(\mathrm{D} / 2)^{2} \\
& \mathrm{D}=\text { diâmetro médio de copa de árvore. }
\end{aligned}
$$

A partir desse cálculo, multiplica-se a superfície de copa pelo número total de árvores levantadas (ALVAREZ et al., 2005), para se chegar ao total de área de cobertura arbórea (árvores/arbustos).

O cálculo da copa de árvore, por meio das imagens obtidas pela fotografia aérea e pela videografia, foi realizado a partir de um corte na imagem que possibilitou retirar as árvores de todo sistema viário e calcular a cobertura arbórea não-viária.

Para se calcular a cobertura arbórea viária subtraiu-se do total de cobertura arbórea a cobertura arbórea nãoviária. Os dados comparativos são apresentados na Tabela 4.

Observando-se a Tabela 4, percebe-se que o levantamento em campo foi mais semelhante à videografia de 2003 que à fotografia aérea de 2000. Apesar de a fotografia aérea ser de 2000 e o levantamento em campo, de 2001 (ALVAREZ, 2004), as alterações de arborização de calçadas não poderiam ter sido tão drásticas, de 2000 para 2001, reduzindo o valor em 5,7 vezes, uma vez que a cobertura arbórea total da área reduziu-se em 1,93\%. A diferença deve-se, provavelmente, à diferença espectral de contraste entre os métodos utilizados. O método com x fotografia aérea não permitiu uma boa seleção no momento do corte, o que dificultou a separação correta entre o que era árvore de calçada e o resto. De outra forma, a videografia foi um método que permitiu, por meio de infravermelho, que as árvores fossem mais bem destacadas.

O porcentual de cobertura arbórea de árvores de calçada corresponde a 1,10\% do total, enquanto que dados como os de Maco \& McPherson (2002) variaram de 4 a 46\%. Caso se analise a cobertura arbórea da área das calçadas em relação à área total, esse porcentual estaria longe do recomendado por esses autores, que é de $25 \%$.

Tabela 4 - Área e porcentual de cobertura arbórea de calçadas do Bairro Santa Cecília, Piracicaba, Estado de São Paulo, por meio de levantamento em campo, fotografia aérea e videografia, nos anos de 2000, 2001 e 2003.

Table 4 - Area and percentage of sidewalk tree cover in the Santa Cecília neighborhood, Piracicaba, State of São Paulo, by field survey, aerial photography and videography in 2000, 2001 and 2003.

\begin{tabular}{lccc}
\hline Cobertura arbórea de calçadas & & Área $\left(\mathrm{m}^{2}\right)$ & 2001 \\
& 2000 & $9.440,49$ & 2003 \\
\hline Levantamento em campo & - & & $9.329,18$ \\
Fotografia aérea & $68.523,42$ & $(\%)$ & $13.071,99$ \\
Videografia & - & 0,77 & 0,76 \\
& - & - & - \\
Levantamento em campo & 7,17 & - & 1,10 \\
Fotografia aérea & - & & \\
Videografia & & & \\
\hline
\end{tabular}




\section{CONCLUSÕES}

A caracterização da vegetação urbana foi feita de maneira coerente com a realidade, tanto utilizando $\mathrm{x}$ a fotografia aérea, como a videografia, quando se analisam os valores de Índice de Kappa e de Exatidão Global.

A videografia mostrou-se mais eficiente para calcular o Índice de Cobertura Vegetal em Área Urbana (ICVAU) e o Índice de Verde por Habitante (IVH) que a fotografia aérea.

A videografia foi o método mais adequado para estudo de árvores de calçadas, também.

\section{REFERÊNCIAS}

ALVAREZ, I.A; VELASCO, G.D; BARBIN, H.S.; LIMA, A.M.L.P; COUTO, H.T.Z. Comparison of two sampling methods for estimating urban tree density. Journal of Arboriculture, v. 31, n.5, p.209-214, 2005.

ALVAREZ, I.A. Qualidade do espaço verde urbano: uma proposta de índice de avaliação. Piracicaba, 2004. 187 p. Tese (Doutorado) - Escola Superior de Agricultura "Luiz de Queiroz”, Universidade de São Paulo.

CONGALtON, R.G.; GREEN, K. Assessing the accuracy remotely sensed data: principles and pactices. New York: Lewis Publishers, 1999. 137 p.

COUTO, H.T.Z.; VETORAZZI, C.A.; FERRAZ, S.F. de B.; POMPERMAYER NETO P. Airbone videography as a data source for de decisionmaking process in agriculture. In: INTERNATIONAL CONFERENCE ON GEOSPATIAL INFORMATION IN AGRICULTURE AND FORESTRY, 2., Lake Buena Vista, 2000. Proceedings. Lake Buena Vista: ERIM, 2000. p. 459-461.

HARDER, I. C. F.; RIBEIRO, R. C. S.; TAVARES, A. R. Índices de área verde e cobertura vegetal para as praças do Município de Vinhedo, SP. Revista Árvore, Viçosa, v. 30, n. 2, p. 277-282, 2006.

Revista Árvore, Viçosa-MG, v.34, n.4, p.691-698, 2010
GUZZO, P. Estudo dos Espaços livres de uso público da cidade de Ribeirão Preto/SP, com detalhamento da cobertura vegetal e áreas verdes públicas de dois setores urbanos. Rio Claro, 1999. 125p. Dissertação (M.Sc.) - Instituto de Geociências e Ciências Exatas / Campus de Rio Claro, Universidade Estadual Paulista “Júlio de Mesquita Filho”.

JENSEN, J.R. Introductory digital image processing: a remote sensing perspective. 2 . ed. New Jersey: Prentice Hall, 1996. 316 p.

LANDIS, J.R.; KOCH, G.G. The measurement of observer agreement for categorical data.

Biometrics. Vol. 33, n. 1, p. 159-74, 1977.

MACO, S.E.; McPHERSON, E.G. Assessing canopy cover over streets and sidewalks in street tree populations. Journal of

Arboriculture, v. 28, n. 6, 2002.

POMPERMAYER NETO, P. Utilização da videografia aérea na detecção de áreas com deficiências nutricionais em plantios de eucalipto. Piracicaba, 2002. 75 p. Dissertação (Mestrado) Escola Superior de Agricultura "Luiz de Queiroz”, Universidade de São Paulo.

POWELL, R.L., ROBERTS D.A., DENNISON, P.E., HESS, L.L. Sub-pixel mapping of urban land cover using multiple end member spectral mixture analysis: Manaus, Brazil. Remote Sensing of Environment, v.106, n. 2, p 253.-267, 2007.

ESPÍRITO-SANTO, F.D.; SHIMABUKURO, Y.E. Validação do mapeamento de uma área de floresta tropical com o uso de imagens de videografia aérea e dados de levantamento de campo. Revista Árvore, v. 29, n. 2, p. 227-239, 2005.

SHIMABUKURO, M.T. Avaliação de classificadores espectrais de imagens TM LANDSAT em áreas rurais densamente ocupadas - o caso da região de Brotas e Torrinha, São Paulo, Brasil. Campinas, 1996. 177 p. Dissertação (Mestrado) - Instituto de Biologia, Universidade Estadual de Campinas.

SILVA FILHO, D.F.; PIZETA, P.U.C.; ALMEIDA, J.B.S.; PIVETA, K.F.L.; FERRALDO, A.S. Banco de dados relacional para cadastro, avaliação e manejo da arborização em vias públicas. Revista Árvore, Viçosa, v. 26, n. 5, 2002.

SILVA FILHO, D.F. Videografia aérea multiespectral em Silvicultura Urbana. Ambiência, Guarapuava, PR, v. 2, p. 55-68, 2006. 